\title{
PELATIHAN KEHUMASAN DAN MEDIA BAGI STAF KPU PROVINSI SULAWESI SELATAN
}

\author{
Zulkarnain Hamson ${ }^{1 *}$, Fyan Andinasari Kuen ${ }^{2}$, Sitti Mirsa ${ }^{3}$ Irwan Muin ${ }^{4}$ \\ ${ }^{1,2}$ Prodi Ilmu Komunikasi, Fakultas Ilmu Sosial dan Ilmu Politik, Universitas Indonesia Timur, Indonesia \\ ${ }^{3}$ Prodi Ilmu Pemerintahan, Fakultas IImu Sosial dan Ilmu Politik, Universitas Indonesia Timur, Indonesia \\ ${ }^{4}$ Prodi Ilmu Hukum, Program Pascasarjana, Universitas Indonesia Timur, Indonesia \\ 'zulkarnain.hamson@uit.ac.id 2fyan.andinasari@uit.ac.id \\ sitti.mirsa_0914107703@uit.ac.id ${ }^{4}$ irwan.muin@uit.ac.id
}

\begin{abstract}
ABSTRAK
Abstrak: Hubungan Masyarakat yang lazim dikenal sebagai penghubung antara institusi, lembaga dengan masyarakat, terkait publikasi atau penjelasan kinerja, disingkat menjadi (Humas). Kedudukannya dalam struktur lembaga yang menaunginya, dikenal dalam berbagai bentuk, diantaranya, Biro, Bagian, Bidang, Unit, dipimpin oleh seorang pejabat yang diberikan kewenangan berdasarkan Surat Keputusan (SK), yang menguraikan Tujuan, Pokok dan Fungsi (Tupoksi). Salah satu fungsi pokok Humas adalah pembuatan rilis berita, untuk disebarluaskan kepada masyarakat, terkait kinerja lembaga atau institusi yang membentuknya. Untuk fungsi kerja itu Humas berkewajiban membangun kemitraan dengan media, baik cetak, elektronika maupun online (Website). Berdasarkan pertimbangan pengembangan keilmuan Humas, juga pers atau kewartawanan, dilaksanakan kegiatan pelatihan bagi Staf Kantor Komisi Pemilihan Umum (KPU) Provinsi Sulawesi Selatan (Sulsel), yang dengannya diharapkan tercapai pemahaman yang paripurna dalam kerja-kerja kehumasan yang harus mereka jalankan dalam menghadapi Pemilihan Umum (Pemilu), baik legislatif, eksekutif, maupun Pemilihan Langsung Kepala Daerah (Pilkada).
\end{abstract}

Kata Kunci: Pelatihan, Kehumasan, Media, KPU

Abstract: Public Relations, commonly known as a liaison between institutions, institutions and society, related to publications or explanations of performance, abbreviated as (Public Relations). Its position in the institutional structure that houses it, is known in various forms, including, Bureau, Section, Field, Unit, led by an official who is given authority based on a Decree, which outlines the Purpose, Principle and Function (Auth). One of the main functions of Public Relations is making news releases, to be disseminated to the public, related to the performance of the institutions or institutions that shape it. For this work function, $P R$ is obliged to build partnerships with the media, both print, electronics and online (Website). Based on consideration of scientific development of Public Relations, as well as the press or journalism, a training activity was held for the Staff of the General Election Commission (KPU) Office of South Sulawesi Province, with which it is hoped that a complete understanding of public relations work must be carried out in the face of General Elections (Elections), both the legislative, executive, and the Direct Election of Regional Heads (Pilkada).

Keywords: Training, Public Relations, Media, KPU 


\section{A. LATAR BELAKANG}

Komisi Pemilihan Umum (KPU) adalah lembaga Penyelenggara Pemilu yang bersifat nasional, tetap, dan mandiri yang bertugas melaksanakan Pemilu. KPU Provinsi dan KPU Kabupaten/Kota adalah Penyelenggara Pemilu di Provinsi dan Kabupaten/Kota. Wilayah kerja KPU meliputi seluruh wilayah Negara Kesatuan Republik Indonesia.(Mamba Ari \& Razak, M.R.R; Majidi, Andi;Ahmad, 2018) KPU Provinsi Sulawesi Selatan, melalui bidang kerjasama Wakil Rektor IV Universitas Indonesia Timur (UIT) Makassar, telah menjadi mitra dalam pelaksanaan Tridharma Perguruan Tinggi, juga dalam penempatan mahasiswa Praktik Kerja Lapangan (PKL), sejak tahun 2014.

Kerja KPU dalam mengawal pemilu tidak sedikit mengalami kendala, baik dalam sosialisasi maupun pelaksanaan pemungutan suara hingga penetapan hasil pemilu. Untuk itu dibutuhkan partisipasi masyarakat juga kemampuan menyampaikan informasi yang akurat melalui lembaga humas yang ditugaskan membantu sekretariat KPU (Saputra, 2018). Humas adalah sesuatu yang merangkum keseluruhan komunikasi yang terencana, baik itu ke dalam maupun ke luar, antara suatu organisasi dengan semua khalayaknya dalam rangka mencapai tujuan tujuan spesifik yang berlandaskan pada saling pengertian.(Ruslan, Rosady, SH, 2014). Media adalah suatu alat perantara atau pengantar yang berfungsi untuk menyalurkan pesan atau informasi dari suatu sumber kepada penerima pesan. Pendapat lain mengatakan arti media adalah segala bentuk saluran yang dapat digunakan untuk menyampaikan informasi atau pesan. Dengan kata lain, media dapat didefinisikan sebagai sarana untuk menyampaikan suatu pesan. Secara etimologi kata "media" berasal dari bahasa Latin, yaitu "medius" yang artinya "tengah, perantara atau pengantar". Istilah "media" pada umumnya merujuk pada sesuatu yang dijadikan sebagai wadah, alat, atau sarana untuk melakukan komunikasi (Croucher, 2018). Menyadari akan pentingnya dukungan berbagai pihak dalam melancarkan kerja KPU sebagai tugas bangsa dan negara UIT melalui Lembaga Penelitian dan Pengabdian kepada Masyarakat (LPPM), melaksanakan pelatihan bagi staf kesekretariatan KPU Provinsi Sulsel, sebagai bagian dari Pengabdian Masyarakat (Penmas).

\section{B. METODE PELAKSANAAN}

Metode pelaksanaan kegiatan ini, dalam bentuk pelatihan, ceramah dan diskusi. Dilanjutkan dengan praktik penulisan rilis berita, kepada staf Kantor KPU Provinsi Sulsel, atau bahan dasar informasi kegiatan yang akan dikirim ke media massa untuk dipublikasikan. 


\section{Ceramah}

Metode Ceramah digunakan untuk menyampaikan materi secara rinci tentang ilmu kehumasan dan media. Adapun topik yang akan disampaikan antara lain:

a. Pengertian Humas baik secara keilmuan maupun fungsi kerjanya (Ruslan, Rosady, SH, 2014)

b. Mengenal media, media massa dan karakteristiknya

c. Teknik penulisan rilis berita (Valkenburg \& Peter, 2013)

\section{Diskusi}

Metode Diskusi berfungsi mengakomodir pertanyaan atau pemikiran peserta tentang materi yang telah disampaikan. Dari metode diskusi ini dapat kita ketahui atensi dan elaborasi sudut pandang dan pemikiran peserta terhadap materi ceramah.

\section{Praktik}

Metode Praktik bertujuan mengasah keterampilan peserta, dalam menyusun program dan informasi kegiatan dalam bentuk rilis berita. Pada kegiatan praktik, peserta mulai mengenal berbagai kekeliruan dalam kerja kehumasan terkait penyiapan naskah publikasi media, hal itu menimbulkan antusiasme peserta.

\section{HASIL DAN PEMBAHASAN}

Kegiatan pengabdian ini memberikan hasil, diantaranya dapat dikemukakan sebagai berikut:

1. Staf KPU Provinsi Sulsel, menyatakan bahwa sangat banyak sekali manfaat yang diperolehnya, terutama dapat mengetahui berbagai fungsi kerja humas, serta kemitraannya dengan media, dengan berbagai bentuk dan jenis media.

2. Sebagian besar staf KPU Provinsi Sulsel, mengungkapkan bahwa perlu dilakukan kegiatan seperti itu, di tahun-tahun mendatang, terutama di setiap menyambut even pemilu.

Pelaksanaan kegiatan pengabdian ini, dilaksanakan mulai pukul 08.3016.00 WITA. Tempat pelaksanaan Aula Kantor KPU Provinsi Sulsel, jalan Andi Pangerang Pettarani, Kota Makassar.

\section{Ceramah}

Metode Ceramah digunakan untuk menyampaikan materi secara rinci tentang kehumasan dan media. Adapun topik yang disampaikan antara lain:

a. Pengertian Hubungan Masyarakat

b. Teori-teori Humas.

c. Pengertian media, media massa dan format media.

\section{Diskusi}

Metode Diskusi digunakan untuk mengakomodasi pertanyaan atau masukan tentang materi yang telah disampaikan. Dari metode 
diskusi ini dapat diketahui antusias peserta sangat tinggi tentang fungsi, peran dan keilmuan praktis yang mendasari humas serta media.

3. Praktik

Metode Praktik digunakan untuk mempraktikkan keterampilan dalam penulisan rilis berita, sistematika tulisan, foto atau gambar, serta pilihan judul yang tepat dan menarik. Pada tahapan ini sebagian besar peserta terlihat canggung, ragu-ragu serta kesulitan memulai merangkai susunan kalimat.

Tabel 1. Materi Pelatihan

\begin{tabular}{llrc}
\hline No & \multicolumn{1}{c}{ Materi } & \multicolumn{1}{c}{ Penyaji } & Waktu \\
\hline 1 & $\begin{array}{l}\text { Mengenal teori dan } \\
\text { tupoksi } \\
\text { kehumasan }\end{array}$ & Fyan Andinasari Kuen & $08.00-09.00$ \\
& & & \\
\hline 2 & $\begin{array}{l}\text { Teori-teori Media, jenis } \\
\text { dan karakter }\end{array}$ & Zulkarnain Hamson & $09.30-10.30$ \\
\hline 3 & $\begin{array}{l}\text { Cara praktis menulis } \\
\text { rilis dan berita }\end{array}$ & Zulkarnain Hamson & $12.30^{-}$ \\
\hline & & & 13.30 \\
\hline \multicolumn{2}{c}{ Total Jam } & 8 Jam \\
\hline
\end{tabular}

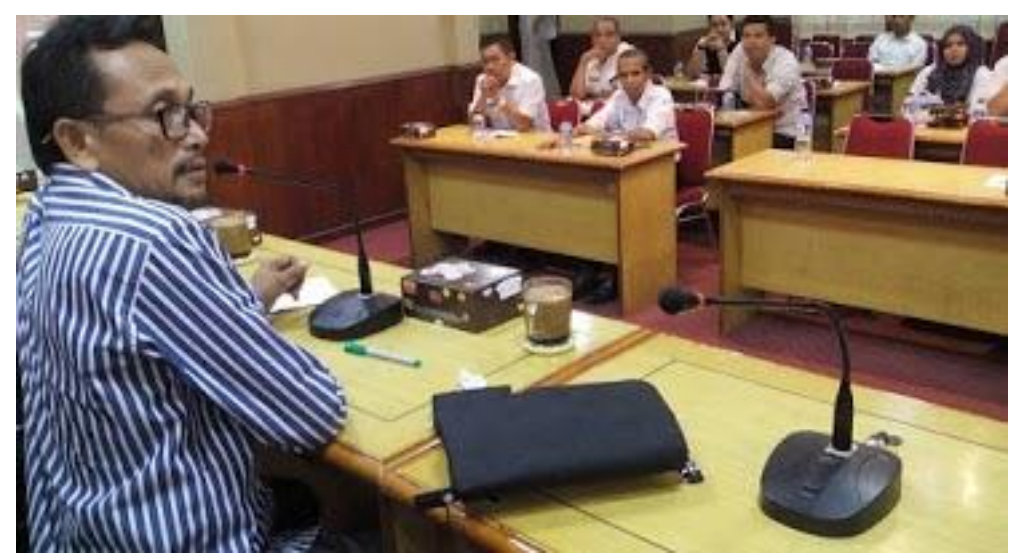

Gambar 1. Suasana Penyampaian Materi

Kegiatan berlangsung efektip, dialogis interaktif, tertib dan lancar.

1. Pada hari pertama pelatihan diikuti 20 orang Staf KPU. Semua peserta mengikuti pelatihan hingga berakhirnya pemaparan dua materi ceramah, teoritis, dengan aktif. Pengukuran keaktifan peserta diketahui melalui banyaknya pertanyaan yang diajukan oleh peserta, semua mengaitkan pertanyaan dengan lini kerja sehari-hari.

2. Pada hari kedua kegiatan pelatihan, memasuki tahapan uji praktek kerja teknis. 20 peserta diminta secara bergantian memaparkan pemahaman pada teori 
kehumasan dan media, selanjutnya dosen pendamping melakukan pembinaan teknis, penulisan berita dan pilihan media, setelah terlebih dahulu meminta peserta menuangkan rencana program sasaran media secara tertulis. Peserta diminta memperagakan cara bagaimana menyusun kalimat pers rilis. Dosen memberi motivasi kepada peserta agar tidak keluar dari rencana program yang telah mereka susun.

Tabel 2. Simulasi Program Unit dan Pilihan Media

\begin{tabular}{clcc}
\hline No & \multicolumn{1}{c}{ Unit } & Program & Media \\
\hline 1 & Staf Divisi Teknis & $\begin{array}{c}\text { Sosialisai Kertas } \\
\text { Suara }\end{array}$ & Televisi \\
\hline 2 & Staf Divisi Hupmas & Jumpa Pers & All Media \\
\hline 3 & $\begin{array}{l}\text { Staf Divisi } \\
\text { Keuangan }\end{array}$ & Publikasi Anggaran & Cetak \& Online \\
\hline 4 & Staf Divisi Hukum & $\begin{array}{c}\text { Sosialisasi UU } \\
\text { Pemilu }\end{array}$ & Televisi \\
\hline 5 & Staf Logistik & Pencetakan Brosur & Radio \\
\hline 6 & $\begin{array}{l}\text { Staf Divisi } \\
\text { Sosialisasi }\end{array}$ & Partisipasi Pemilu & All Media \\
\hline 7 & $\begin{array}{l}\text { Staf } \\
\text { Kesekretariatan }\end{array}$ & Jumpa Pers & All Media \\
\hline
\end{tabular}

3. Peserta diminta menguraikan program yang direncanakan, disesuaikan dengan alokasi anggaran yang tersedia bagi pelaksanaan masing-masing kerja teknis yang ditanganinya. Berdasarkan program yang disusun dan dipaparkan, peserta diminta melakukan pemilihan jenis media, merujuk pada pemaparan materi dan teori di hari pertama.

4. Diperoleh tujuh program kehumasan yang memiliki korelasi dengan media, baik format maupun jenis media yang dipilihnya. Dosen pendamping melakukan pengamatan ada penyusunan program, pembahasan, penetapan jenis media dan metode evaluasinya.

Tabel 3. Kendala Program Unit dan Pilihan Media

\begin{tabular}{|c|c|c|c|c|c|}
\hline No & Unit & Program & Media & Kendala & Solusi \\
\hline 1 & $\begin{array}{l}\text { Staf Divisi } \\
\text { Teknis }\end{array}$ & $\begin{array}{c}\text { Sosialisai } \\
\text { Kertas } \\
\text { Suara }\end{array}$ & Televisi & $\begin{array}{c}\text { Anggaran } \\
\text { terbatas }\end{array}$ & Online \\
\hline 2 & $\begin{array}{l}\text { Staf Divisi } \\
\text { Hupmas }\end{array}$ & Jumpa Pers & $\begin{array}{c}\text { All } \\
\text { Media }\end{array}$ & $\begin{array}{r}\text { Anggaran } \\
\& \text { Waktu }\end{array}$ & $\begin{array}{l}\text { Seleksi } \\
\text { Media }\end{array}$ \\
\hline 3 & $\begin{array}{l}\text { Staf Divisi } \\
\text { Keuangan }\end{array}$ & $\begin{array}{l}\text { Publikasi } \\
\text { Anggaran }\end{array}$ & $\begin{array}{c}\text { Cetak } \\
\& \\
\text { Online }\end{array}$ & $\begin{array}{l}\text { Efektif } \\
\text { pesan }\end{array}$ & Cetak \\
\hline 4 & Staf Divisi & Sosialisasi UU & Televisi & Ketepatan & Cetak \\
\hline
\end{tabular}




\begin{tabular}{|c|c|c|c|c|c|}
\hline & Hukum & Pemilu & & Waktu & $\begin{array}{c}\& \\
\text { Online }\end{array}$ \\
\hline 5 & $\begin{array}{l}\text { Staf } \\
\text { Logistik }\end{array}$ & $\begin{array}{c}\text { Pencetakan } \\
\text { Brosur }\end{array}$ & Radio & $\begin{array}{l}\text { Segmentasi } \\
\text { terbatas }\end{array}$ & $\begin{array}{c}\text { All } \\
\text { Media }\end{array}$ \\
\hline 6 & $\begin{array}{l}\text { Staf Divisi } \\
\text { Sosialisasi }\end{array}$ & $\begin{array}{l}\text { Partisipasi } \\
\text { Pemilu }\end{array}$ & $\begin{array}{c}\text { All } \\
\text { media }\end{array}$ & $\begin{array}{c}\text { Kemasan } \\
\text { pesan }\end{array}$ & $\begin{array}{l}\text { Sosialis } \\
\text { asi } \\
\text { umum }\end{array}$ \\
\hline 7 & $\begin{array}{l}\text { Staf } \\
\text { Kesekretari } \\
\text { atan }\end{array}$ & Jumpa Pers & $\begin{array}{c}\text { All } \\
\text { media }\end{array}$ & $\begin{array}{l}\text { Pengaturan } \\
\text { tempat dan } \\
\text { waktu }\end{array}$ & $\begin{array}{l}\text { Rilis } \\
\text { berita }\end{array}$ \\
\hline
\end{tabular}

Hal-hal yang ditemui sebagai kendala saat pelaksanaan kegiatan, adalah:

1. Anggaran pemilu yang dimiliki KPU terbatas.

2. Waktu kegiatan harus sinkron dan bisa berjalan sesuai tahapan pemilu

3. Pesan yang akan dimuat di berbagai media harus dikemas dengan tepat sasaran baik jenis media maupun audiens yang dituju.

4. Pilihan media harus mempertimbangkan dengan baik kualifikasi dan jangkauan media.

5. Pengaturan tempat dan waktu penyelenggaraan kegiatan jumpa pers, harus memenuhi harapan media.

Solusi dalam pemecahan masalah tersebut, adalah:

1. Keterbatasan anggaran pemilu yang dimiliki KPU diupayakan mampu dimaksimalkan dalam prioritas publikasi.

2. Waktu kegiatan telah disinkron dan bisa berjalan sesuai tahapan publikasi pemilu, dengan pilihan media dan kemasan informasi yang tepat.

3. Pesan yang akan dimuat di berbagai media telah dikemas dengan tepat sasaran baik jenis media maupun audiens yang dituju.

4. Pilihan media telah mempertimbangkan dengan baik kualifikasi dan jangkauan media, pada wilayah sasaran.

5. Pengaturan tempat dan waktu penyelenggaraan kegiatan jumpa pers, sudah mengalami revisi agar memenuhi harapan media.

\section{SIMPULAN DAN SARAN}

Perencanaan kerja humas, bukanlah sesuatu yang sulit jika terlebih dahulu mengalami proses pemahaman dan pengenalan Tupoksi humas, cara mengemas pesan yang akan dikirimkan kepada media disertai pengetahuan pada karakter media serta jenis pesan yang akan dipublikasikan. Pemberian teori dasar kehumasan, yang diikuti dengan 
pemberian materi cara menuliskan rilis berita berdasarkan kaidah jurnalistik, peserta dengan mudah melakukan uji coba pembuatan rilis dan format berita.

\section{UCAPAN TERIMA KASIH}

Tim penulis haturkan terima kasih kepada Lembaga Penelitian dan pengabdian Pada Masyarakat (LPPM) UIT, yang telah membantu penyediaan anggaran kegiatan, Dekan Fakultas Ilmu Sosial dan Ilmu Politik, Rektor dan Wakil Rektor IV UIT, Bidang Humas dan Kerjasama, yang telah membangun kemitraan dengan KPU Provinsi Sulsel, sehingga acara ini dapat terlaksana.

\section{DAFTAR RUJUKAN}

Croucher, S. M. (2018). Mass Communication. In Understanding Communication Theory. https://doi.org/10.4324/9781315796710-10

Mamba Ari, S., \& Razak, M.R.R; Majidi, Andi;Ahmad, J. (Universitas M. S. R. (2018). Pengaruh Perilaku Birokrasi Komisi Pemilihan Umum Terhadap Partisipasi Politik Masyarakat dalam Pemilihan Presiden dan Wakil Presiden Tahun 2014. Knappptma Ke-8.

Ruslan, Rosady, SH, M. (2014). Manajemen Public Relations \& Media Komunikasi. In Manajemen Public Relations \& Media Komunikasi.

Saputra, M. N. (2018). Pelayanan Publik dalam Penyelenggaraan Pemilu di Indonesia. Jurnal Ilmiah Indonesia, 3(3), 119-137.

Trevino, L. K., Lengel, R. H., \& Daft, R. L. (1987). Media Symbolism, Media Richness, and Media Choice in Organizations. Communication Research. https://doi.org/10.1177/009365087014005006

Valkenburg, P. M., \& Peter, J. (2013). The differential susceptibility to media effects model. Journal of Communication. https://doi.org/10.1111/jcom.12024 